\title{
Paper 5G Is Out There: How to Ride the Market Storm and Thrive
}

\author{
Edward Smith ${ }^{1}$ and Mauro Ugolini ${ }^{2}$ \\ ${ }^{1}$ Wokingham U3A, Wokingham, United Kingdom \\ ${ }^{2}$ Department of Engineering, Roma Tre University, Rome, Italy
}

https://doi.org/10.26636/jtit.2021.151521

\begin{abstract}
We examine the changes in the commercial model adopted by the mobile ICT industry, due to the advent of 5G technology. This includes consideration of the challenges involved in rolling out a new infrastructure, which new markets this is likely to open up and how this affects partnering decisions. We show that as technology horizons expand, their degree of overlap increases and previously complimentary technologies may compete with each other, impacting the size of the addressable market. It is expected that $5 \mathrm{G}$, whilst supporting its existing markets, will offer additional machine to machine, low latency and highly reliable services. We consider the synergies and the drivers for adoption for the wider $5 \mathrm{G}$ propositions and consider the impetus for more bandwidth and services and how the new technology impacts selling approaches. We identify the risks and uncertainties for the network providers and the likely requirements for a sustainable $5 G$ business model and will describe our view of the steps necessary for a 5G successful outcome.
\end{abstract}

Keywords-5G, eMBB, mMTC, URLLC.

\section{More than an Evolution}

In this paper we will cover the changes in the commercial model adopted by the mobile ICT industry, due to the advent of 5G technology and the impacts it is likely to engender.

We will examine the challenges offered in rolling out a new infrastructure, which new markets this is likely to open up and how this affects partnering decisions. We will also show that as technology capabilities expand, their degree of overlap increases and previously complimentary technologies can become competition for each other. Competition is likely to impact the size of the market.

We suggest that $5 \mathrm{G}$ will not be just an evolution of $4 \mathrm{G}$ services, supporting its existing markets. The synergies between $5 \mathrm{G}$ and the application space will be examined and the drivers for adoption identified. We will ask where the impetus for more bandwidth might come from and how this will change the way mobile capacity is sold. We will investigate each of the following main propositions, the last two of which require strong partner collaboration, and evaluate the prognosis for their commercial success:
- eMBB, extended massive broadband, representing the evolutionary path from the existing proposition,

- mMTC, massive machine type communications, delivering high density radio services for machine to machine (M2M) applications,

- URLLC, ultrareliable low latency communications, fostering improvements in latency and reliability to allow mission critical applications.

We will examine where the risks and uncertainties for the networks providers are and the likely requirements for a sustainable $5 \mathrm{G}$ business model. We will conclude by presenting our view of the steps necessary for a $5 \mathrm{G}$ successful outcome.

\section{The Impact}

$5 \mathrm{G}$ is expected to provide a user data rate of up to $100 \mathrm{Mbps}$ in the downlink direction, an increase in spectral efficiency, a latency of 1-4 ms, a connection density of up to 1,000,000 devices per $\mathrm{km}^{2}$ and improvements in availability, reliability and energy utilization [1]. An increase in capacity of 5G over LTE by a factor of between 1000 and 5000 fold is anticipated [2], requiring, as a consequence, an increase in backbone capacity [3].

$4 \mathrm{G}$ remains the fastest growing network, reaching 5.6 billion users worldwide by 2022 and consuming $79 \%$ of all mobile data traffic by 2021 . The corresponding figures for $5 \mathrm{G}$ are 400 million subscribers and $1.5 \%$ of traffic [4], [5]. $5 \mathrm{G}$ is expected to generate opportunities, with a global economic impact of 12.3 trillion USD [6], even if the economics and ability to monetize the investment remain unclear [2].

A low to mid-band $5 \mathrm{G}$ network has similar form and cost to an equally dense $4 \mathrm{G}$ implementation. The high bandwidth deployments delivering high performance rely on networks that have considerably more node density than LTE [7], [8]. Unless costs fall dramatically, this will challenge most business cases [7].

Investments in $5 \mathrm{G}$ can be deferred by building on existing LTE infrastructures. For example, network operator 
EE's initial UK implementation ${ }^{1}$ uses $4 G$ to provide the WAN, signaling and control plane, and the $5 \mathrm{G}$ user plane for data [9]. Deployment of 5G could double network costs, with a $60 \%$ increase in capital expenditures, for standalone deployments. Simulation of a $5 \mathrm{G}$ build-out demonstrated that around $20 \%$ more macro-sites would be needed and an increase in new small cells equivalent to $100-150 \%$ of existing macro-cells may be required [10].

Network sharing can reduce total cost of ownership by $30 \%$ and the cost of small cell deployments by $50 \%$, as shown in Fig. 1, while improving network quality, minimizing the impact of urban works and reducing the level of street furniture [10].

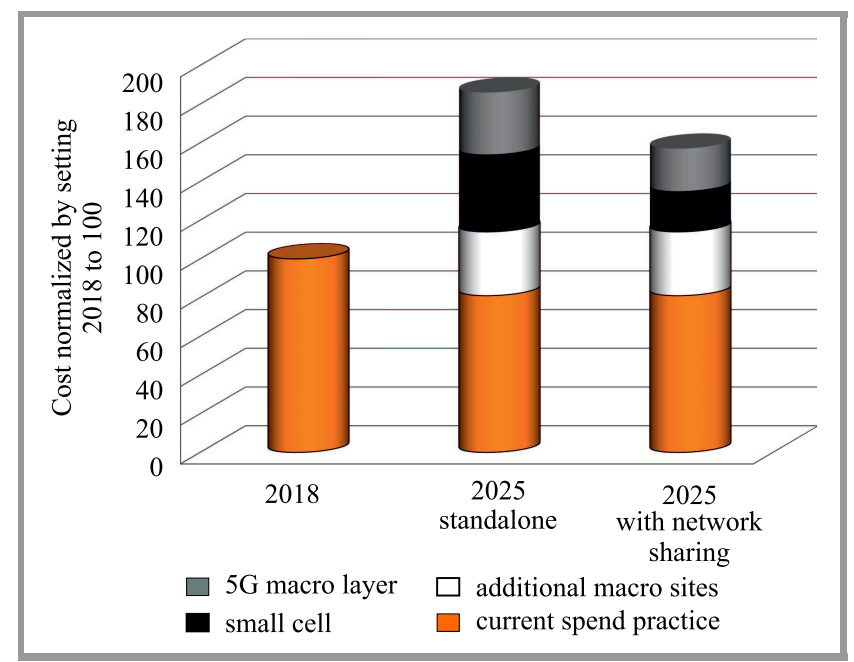

Fig. 1. The impact of network sharing on deployment costs [10].

Software defined networks, which should reduce operational costs, and network function virtualization, impacting capital costs, are often cited as a means of reducing deployment costs. In the short term, the contribution from these is likely to be significantly less than network sharing.

Network slicing is a virtualization technique offering significant advantages for mobile network operators (MNOs), allowing them to operate separate virtual infrastructures, with their own service characteristics across a common physical network. This allows say the operation of a dedicated network slice for the emergency services or to allow a mobile virtual network operator (MVNO) to occupy its own network slice. However, there seems to be little quantitative information showing how much network slicing will contribute to the overall $5 \mathrm{G}$ business case.

$5 \mathrm{G}$ will focus initially on eMBB and as the service matures, URLLC and mMTC will be added [9]. So far, we have

\footnotetext{
${ }^{1}$ In January 2020, following a security review, the UK government limited the involvement of Huawei to $35 \%$ of non-core $5 \mathrm{G}$ infrastructure. In May, the US prevented Huawei from incorporating American technology in their solutions, undermining Huawei's supply chain and creating delivery uncertainty. A subsequent UK government review has prohibited UK telecommunications providers from buying new infrastructure from Huawei and requiring the removal of their equipment from MNO's 5G infrastructures by 2027 .
}

considered $5 \mathrm{G}$ in terms of its capabilities and managing the cost of its introduction. We now progress to examine the role of competition between technologies.

\section{Competition Amongst Communication Technologies}

Technology introduction can be commercially hazardous. For example, ISDN (Integrated Services Digital Network) a network supporting digital voice and data services, enjoyed limited market success, before being displaced by broadband services for data and more recently SIP (Session Initiation Protocol) - a method of setting up associations across IP, mainly used for voice services. Similarly SMDS (Switched Multimegabit Data Service) and ATM (Asynchronous Transfer Mode) - a high speed connection orientated service, had short commercial lives, yielding the high speed data space to MPLS (Multiprotocol Label Switching) - a high speed service optimized for IP.

Even where technologies have been successful, longevity brings its own issues and many mobile applications still widely exploit GPRS (General Packet Radio Services) [11], making it difficult to eliminate the costs associated with the old technology, to maximize the revenues accruing the new technology base.

A number of use cases posited for $5 \mathrm{G}$ demand high bandwidth, but not necessarily mobility, making ultra broadband services a viable option [12]. Further, wireless LAN capabilities have supported the growth in use of mobile devices, but can divert traffic away from the mobile network [13]. New Wi-Fi standards (802.11ax, also known as Wi-Fi 6) support dense M2M environments, improving the average throughput by a factor of at least four [14]. In the mMTC area, wireless networks using low power consumption and unlicensed spectrum also provide competition.

Having discussed a number of cases where the success of a technology has been impacted by the emergence of alternatives and the capabilities of existing technologies, which are more established, we move onto consider the area of the market for massive broadband capabilities.

\section{The Market For Radio Broadband (EMBB)}

eMBB represents an evolution of the existing mobile market place, where we begin our analysis of its commercial position. Figure 2 shows the existing usage for mobile services, with the growth in traffic being driven by video.

How much of the new value generated by $5 \mathrm{G}$ will flow to mobile network operators (MNOs) is uncertain. As LTE evolved, MNOs experienced rapid traffic growth from overthe-top providers video and declining average revenue per user due to intense price competition. Ultimately, wireless carriers have focused on lower cost per bit to fend off the risk of falling behind competitors [15]. 


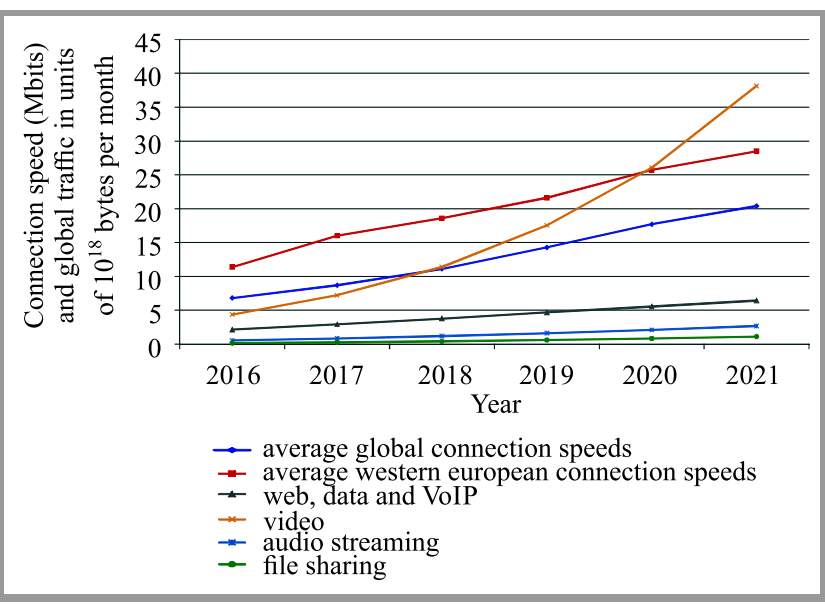

Fig. 2. Expected connection speeds and usage for mobile networks going forward [5].

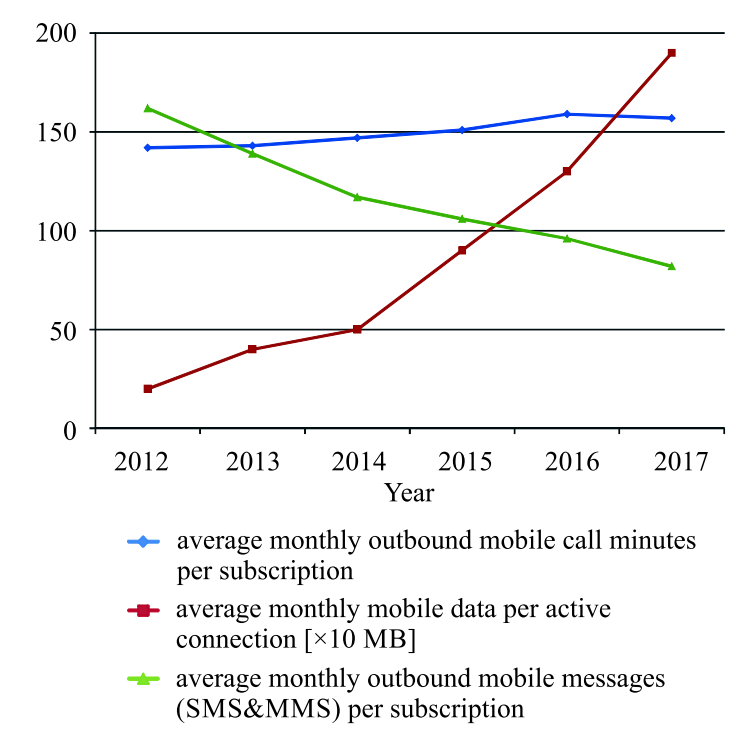

Fig. 3. UK mobile network traffic volumes [16].

As an example, Ofcom report that in the UK the average monthly data use per residential fixed broadband connection and per mobile SIM increased in 2017 by over $40 \%$, to $190 \mathrm{~GB}$ and $1.9 \mathrm{~GB}$ respectively [16]. The Ofcom derived figures for mobile network traffic volumes as a function of time are shown in Fig. 3. Figure 4 clearly shows that whilst data growth is expected to support revenue increase, revenue accumulation lags traffic growth, and this situation, together with changes in tariffing strategies from prepaid approaches to pay-monthly services, are characteristic of a mature market, where costs are imperative and much differentiation comes from creative tariffing. It is expected that this pattern of revenue growth is typical of most EU countries despite the rapid growth in subscribers and higher data volumes seen across the world [15].

In addition, we see that in the UK $69 \%$ people connected to Wi-Fi rather than cellular networks from their mobile devices [17]. During the peak commuter time of 5 and $6 \mathrm{pm}$

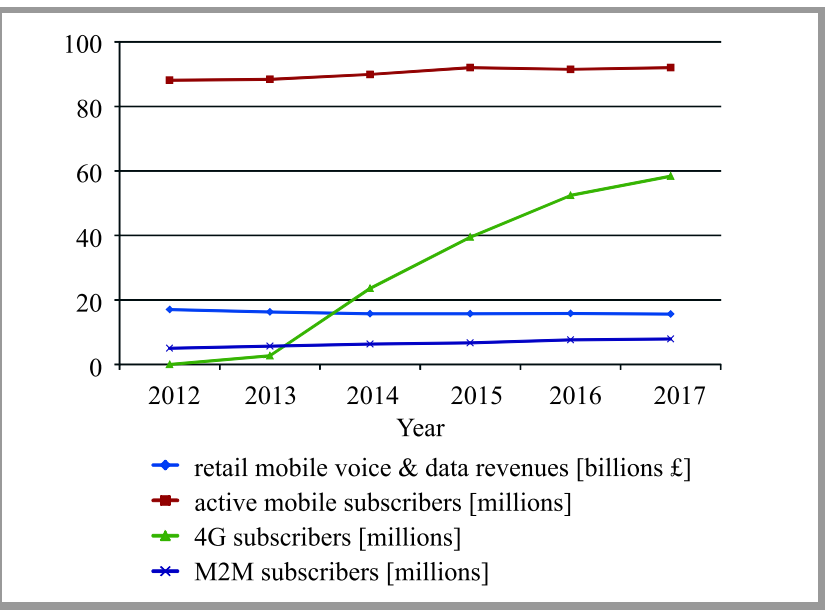

Fig. 4. Mobile subscriber and revenue details from the UK [16].

data volumes on cellular networks peaked, while Wi-Fi use was higher between 6 and $10 \mathrm{pm}$, transferring more data over Wi-Fi than on mobile networks [17]. Actually, this circumstance is not just typical of the UK, because these observations are consistent with global trends reported elsewhere [5].

After this exam of the proposition which forms the base case for $5 \mathrm{G}$, we move on to consider the segment that serves machine to machine communications.

\section{The Market for Machine Communications (MMTC)}

mMTC offers density of the order of 1000000 nodes per $\mathrm{km}^{2}$ [1], with an evolution path from $4 \mathrm{G}$ services. Cisco predicts a rapid rise in the number of $\mathrm{M} 2 \mathrm{M}$ connections, but only a third of them connected to a mobile network. Numbers of mobile network connected and low power wide area (LPWA) M2M devices appear to be growing rapidly. Cisco believes that connected home applications are expected to have the largest share by 2023 , but the connected car will be the fastest growing application [14]. Gartner, on the other hand, believes that initially outdoor surveillance cameras will be the largest M2M market, but will be surpassed by connected cars in 2023 [18].

Figure 4 shows the take-up of M2M subscriptions in the $\mathrm{UK}$, as an example, and Table 1 gives the picture on a worldwide basis.

Worldwide, smart meters provide an example of an M2M network where instrumentation, networks and systems blend to provide a solution. A system integrator leads on the contract and coordinates delivery, but MNOs provide only some communications elements of the solution. They take less of the risk, but the system integrator orchestrates the opportunity to add value in terms of additional services. Most smart meter solutions use mixed technologies, including $2 \mathrm{G}$ mobile, multipoint radio and power line technology, with systems integration being performed by 
a power distribution company in Italy and an independent integrator in the UK. MNOs therefore need to modify their view of the market and their commercial approach, needing different commercial skills and approaches to partnership [11].

Table 1

M2M projected connections [14]

\begin{tabular}{|l|c|c|c|}
\hline \multicolumn{1}{|c|}{$\begin{array}{c}\text { Technology } \\
\text { (total values shown) }\end{array}$} & $\begin{array}{c}\text { Billions } \\
\text { connections } \\
\text { in 2018 }\end{array}$ & $\begin{array}{c}\text { Billions } \\
\text { connections } \\
\text { in 2023 }\end{array}$ & CAGR \\
\hline \hline Networked M2M devices & 5.90 & 14.70 & $19 \%$ \\
\hline $\begin{array}{l}\text { M2M devices connected } \\
\text { to a mobile network }\end{array}$ & 1.14 & 4.45 & $31.0 \%$ \\
\hline $\begin{array}{l}\text { Smartphones connected } \\
\text { to a mobile network }\end{array}$ & 4.05 & 5.37 & $5.8 \%$ \\
\hline LWPA connections & 0.22 & 1.88 & $530 \%$ \\
\hline Mobile connections & 5.10 & 5.70 & $2.0 \%$ \\
\hline
\end{tabular}

Low power wide area networks (LPWA) supports M2M applications requiring low bandwidth, wide geographic coverage and low power consumption, module and connectivity costs, addressing needs that cellular networks cannot meet by themselves. LPWA will grow from $2.5 \%$ of M2M connections in 2018 to $13 \%$ by 2023 , from 223 million to 1.9 billion globally [14] and is expected to compete fiercely with $5 \mathrm{G}$.

LoRaWAN is a proprietary LPWA solution, uses unlicensed spectrum $(868 \mathrm{MHz})$ and is limited to a transmission power of $25 \mathrm{~mW}$ or less. It permits the installation of a gateway at arbitrary points not governed by installation and regulations issues. LoRaWAN solutions have been used to monitor traffic flows, view pedestrian crossings and, as an example, Thames Water in the UK has considered them for their smart meters. Such networks are suitable only for small data packets, unsuitable for mission critical applications and support devices whose batteries need to last many years.

5G technologies can support a range of smart city scenarios as demonstrated by the 2019 FITCE congress [19], which included papers on autonomous vehicles and virtual reality (VR) enhanced tourism, fiber to the antenna, fiber based and $5 \mathrm{G}$ costs models for smart city applications and the costs and benefits of deploying $5 \mathrm{G}$ enabled light poles. Work has also been performed to investigate the potential, economically sustainable, business models for $5 \mathrm{G}$ and network slicing. Although smart cities are a key application, local authorities are unsure of the requirements and their supporting business cases, creating a barrier to deployment [20].

Whilst the machine to machine segment is an evolution of the 4G standards, ultra-reliable low latency communication (URLLC) is not, and represents a number of challenges which are covered in the next section of the paper.

\section{The Market for Low Latency Communications (URLLC)}

The expected latency delay for eMBB is $10 \mathrm{~ms}$ [3], although the target is set at $4 \mathrm{~ms}$ [1]. To meet the sub $1 \mathrm{~ms}$ requirement [1] for URLLC, performance targets of $0.3 \mathrm{~ms}$ device processing, $0.1 \mathrm{~ms}$ delay each way across the radio network and $0.5 \mathrm{~ms}$ within the core network are needed [21], as illustrated in Fig. 5.

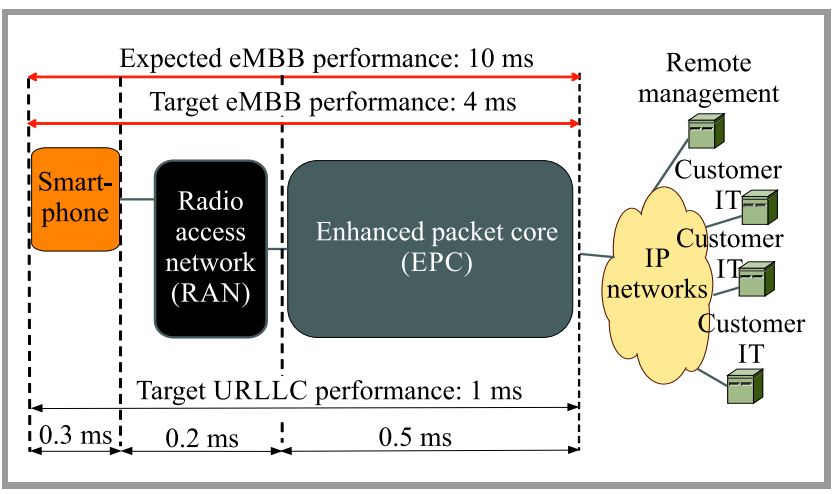

Fig. 5. URLLC latency requirements.

This requirement for coverage of a small area and the use of a high frequency radio interface is commercially challenging and a private network or hybrid solution may be more effective than the MNO network. For example, surgical applications are unlikely to be remote, but take the form of microsurgery within a hospital, using radio to replace delicate cable connections [22]. Industrial use is another use case, where private $5 \mathrm{G}$ networks connecting to the public networks could be used. Such use cases may use multiple providers [14].

URLLC will support augmented reality (AR), virtual reality (VR), edge computing and autonomous vehicles [23], but these technologies have not so far achieved significant market penetration. It is believed that immersive multimedia environments have high market potential, with gaming being a key focus. Edge computing has yet to be defined in detail [22] and in some cases MVNO may add operational complexity by requesting that devices under their control are included in an MNO's infrastructure.

Connected cars may not need $5 \mathrm{G}$, but will be able to use its enhancements and autonomous vehicles may require it [24].

We now move onto make an overview assessment of the $5 \mathrm{G}$ market place.

\section{Market Analysis}

The Braudel rule states that "freedom becomes value when it changes the limits of the possible in the structures of everyday life" [25]. We now look at the three key application areas (eMBB, mMTC, URLLC) in turn and identify 
which factors allow that application to meet the requirements of Braudel's rule.

The growth in mobile traffic appears to have been driven, historically, by a killer application, as shown in Table 2 .

Table 2

The mobile generations and their associated killer applications

\begin{tabular}{|c|c|c|}
\hline Generation & Killer application & Year launched \\
\hline \hline Analog & Mobile business voice & 1986 \\
\hline $2 \mathrm{G}$ & SMS and consumer mobility & 1992 \\
\hline 3G & Smartphone and data & 2003 \\
\hline 4G & Video and OTT applications & 2012 \\
\hline $5 \mathrm{G}$ & $?$ & 2019 \\
\hline
\end{tabular}

Figure 6 shows the growth in smartphone sales which begins when $3 \mathrm{G}$ provided the highest data speeds and continued to accelerate with the introduction of $4 \mathrm{G}$, levelling off before $4 \mathrm{G}$ became the dominant mobile technology. This Cisco estimate to be between 2019 and 2020 [5].

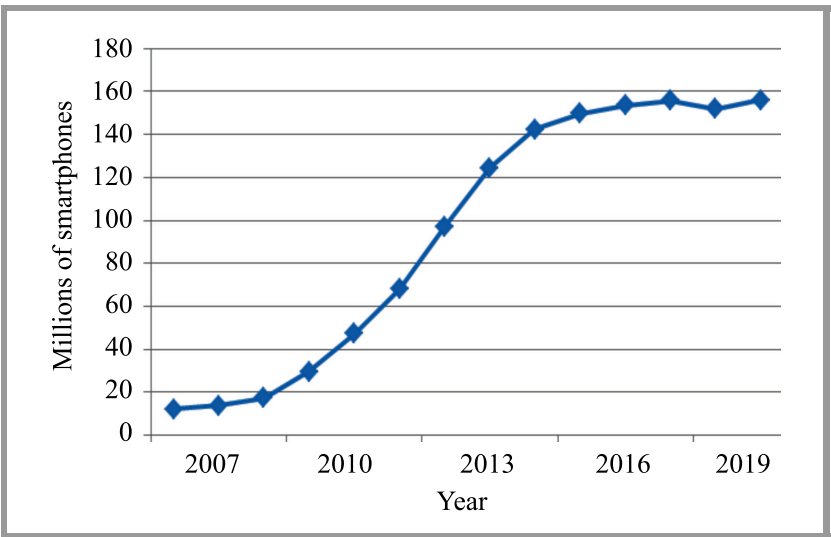

Fig. 6. The saturating smartphone market [26].

As a further example of a situation that is common in other European countries, plotting Ofcom produced figures for data volumes in the UK. This is expected to be typical for the EU) [16] against the revenues of Facebook [27] and Netflix [28]. We see, as shown in Fig. 7, a linear relationship consistent with a link between growth in mobile data and the development of video based, over-the-top provider (OTT), services.

In a recent survey McKinsey found that the majority of chief technology officers (CTO) see enhanced mobile broadband (eMBB) and the Internet of Things (IoT) as the most significant applications for 5G. The uncertain economics of $5 \mathrm{G}$ are encouraging the evaluation of alternative business models, which will need investment in operational support systems (OSS) and business support systems (BSS), to provide the required service wrap [29].

The development of business cases, operations and maintenance strategies and commercial strategies, significantly lags strategies for pilots and technology. The business case

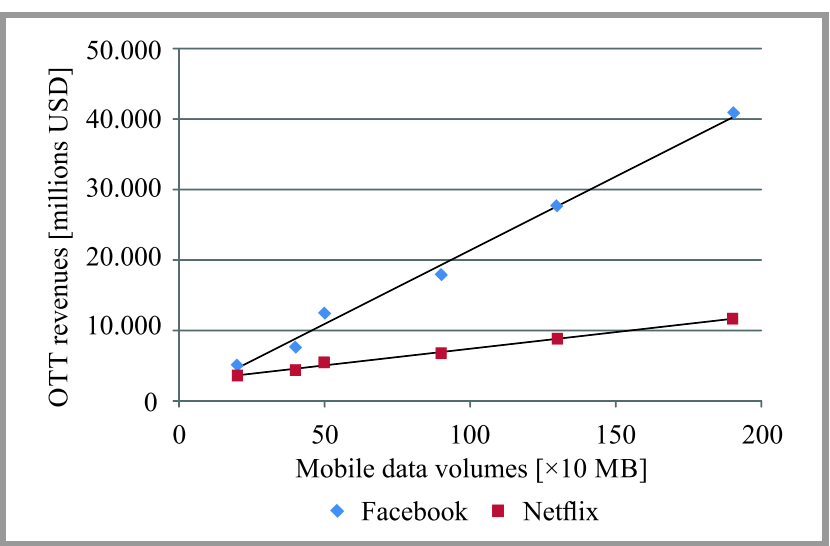

Fig. 7. The relationship between mobile data volumes and new applications media revenues [16], [27], [28].

was the top concern of all European CTOs, contrasting with $11 \%$ in North America.

Operators primarily see $5 \mathrm{G}$ as an opportunity to establish network leadership. M2M appears initially not to be a core objective for $5 \mathrm{G}$, suggesting that the existing M2M capability is considered sufficient for most use cases [29]. Although URLLC has significant potential, it is not yet a major area of investment and its applicability is open to question. European feedback is skeptical about the new use cases.

Delivering the new use cases is critical dependent on partnership, but whilst MNOs are proficient collaborating on standards, they have been less effective in collaborating with third parties. Investment in OSS and BSS is also a concern. However, much of the value of M2M will be generated from advanced network capabilities, which is the MNO's core competence [29].

Exploiting Keen and Mackintosh's interpretation ${ }^{2}$ of Braudel's view of product adoption yields the concepts presented in Table 3.

Table 3

Examining the maturity of 5G technology in terms of Keen and Mackintosh's matrix

\begin{tabular}{|c|c|c|c|}
\hline & Promise & $\begin{array}{c}\text { Chaos } \\
\text { and clutter }\end{array}$ & $\begin{array}{c}\text { Business } \\
\text { mainstream }\end{array}$ \\
\hline \hline Freedom & Monitor closely & Experiment & Make strategic \\
\hline Convenience & Ignore & Avoid & $\begin{array}{c}\text { Incorporate } \\
\text { selectively }\end{array}$ \\
\hline Feature & Distrust & Retreat & $\begin{array}{c}\text { Buy at right } \\
\text { price }\end{array}$ \\
\hline $\begin{array}{c}\text { No clear } \\
\text { target }\end{array}$ & Do not invest & Short sell stock & $\begin{array}{c}\text { Wish you had } \\
\text { bought it }\end{array}$ \\
\hline
\end{tabular}

eMBB is a mainstream use case, but delivers much more bandwidth than appears to be required. An average mobile broadband speed of 43.9 Mbps is envisioned for 2023 [14],

\footnotetext{
${ }^{2}$ Keen and Mackintosh matrix is a formal, space-time conceptualization that is used to delineate the impact of the analyzed technology, and a taxonomy of the technology-based applications.
} 
which is sufficient for ultra high-definition (UHD) video. Yet 5G speeds will be 13 times higher than this by 2023, with an average bandwidth of $575 \mathrm{Mbps}$ [5]. The challenge for the product management function within an MNO is to identify what will take this from "feature" to "freedom" as social media/video did for $4 \mathrm{G}$.

The smart meter use case, described earlier, illustrates some of the pitfalls of the mMTC proposition, which splits between high bandwidth requirements, e.g. closed circuit television (CCTV) and connected cars and low bandwidth and low power applications (e.g. remote sensors). Some of the low power applications generate freedoms but have attracted competition from other technologies. Connected cars appear to be an interesting use-case, but it is unclear why this need cannot be satisfied by eMBB. To take advantage of this, as a revenue opportunity, MNOs need to work closely with the motor industry.

On present evidence it would seem that the high bandwidth case is at the convenience level and low bandwidth at low power is at the freedom level, but with well-established and attractive competition. Many applications require integration into a wider solution and therefore need bringing into line with a solution's business.

URLLC is the proposition at the earliest stage of development, with some clear technical challenges. This coupled with the role of third parties and private networks in its delivery make it likely that this will be a complex and costly proposition to deliver. Most use cases look to be convenience or feature stage. Automated vehicles look the nearest to a freedom, but existing developments of invehicle sensors and intelligence, coupled with information from other vehicles and roadside units, should be capable of being satisfied with a response time of $10 \mathrm{~ms}$ as opposed to $1 \mathrm{~ms}$.

The games industry is an innovative market place, which is said to need low latency. The migration is towards mobile and app-based gaming platforms and growth of access using mobile technology make it demanding of a mobile platform. Multiplatform games are the most likely to use VR, which will demand high bandwidth, particularly in its high definition form. Multiplayer games have strict latency requirements, with any latency over $75 \mathrm{~ms}$ or so causing players and actions to fall out of synchronization. However, a $75 \mathrm{~ms}$ response time is within current $4 \mathrm{G}$ capabilities and those of eMBB's. It may be a freedom for $5 \mathrm{G}$ but it does not seem to require URLCC, which is the most uncertain business area and needs the most development.

\section{Conclusions}

We have examined the challenges offered in rolling out a new infrastructure, which new markets are likely to open and how this affects partnering decisions, showing that as technology capabilities expand their degree of overlap increases. However, previously complimentary technologies can become competition for each other, impacting the size of the market.
Developing 5G successor technologies is likely to be an expensive business, particularly given the increased base station densities that the new technology demands. We reassert the view made by others that network infrastructure sharing provides a way of mitigating some of the costs, but other avenues such as automation need to be explored.

We believe that the demand for any product is fueled by customer needs and wants and that there are several technologies that meet many of the needs addressed by $5 \mathrm{G}$. The hazardous nature of the route to commercial success is outlined with descriptions of several casualties of the invisible hand of the market.

The massive broadband market is expected to be the provider of the lion's share of mobile revenues, but this market has become price sensitive and much traffic is offloaded onto broadband Wi-Fi connections. Whilst the detail of this is expressed in terms of the UK market, we expect the principles to extend to the rest of Europe.

The evolution of low latency and machine to machine services was examined, in particular considering the low power segment of the latter. This is an area where mobile operators face existing, established competition, with a strong record of having the necessary systems integration skills. The market for low latency services appears to be harder to define and refers to supporting technologies which in themselves are not well established and at present niche applications.

We attempted to pull the analysis together by distilling the needs and wants of the market place into Braudel's rule, focusing on the impact of the technology on the limits of everyday life. The applications, spurring the growth across the generations of mobile technology, were unclear at the time of technology launch: SMS for $2 \mathrm{G}$, the smartphone and data for $3 \mathrm{G}$ and video and OTT applications for $4 \mathrm{G}$.

The pressure is on mobile operators to embrace the new opportunity and not be left behind technologically, but what will drive the adoption by end customers? As before this is not obvious and whilst the new applications identified by mMTC and URLLC may make a difference, there is no clear indication that this will be sufficient. As McKinsey have shown, in Europe at least, business cases are incomplete and the biggest worry for operators. A better understanding of the likely development of the market is vital and something it is in the interest of academia, regulators, adjacent sectors and operators to acquire. Whilst it's true that a technologically driven white knight has ridden to the rescue in the past, it has always squeezed the profits of the operators in return.

In short, MNO need to understand the priority applications to focus on. Approaches involving the building of utility models, partnership analysis and optimization may be helpful in analyzing through the complexity of the market. To summarize, we believe that $5 \mathrm{G}$ increases the capability overlap with terrestrial services and requires further non-consumer markets to be addressed to generate a sus- 
tainable business model. Both factors require a change in thinking from the MNO industry, if a successful outcome is to be achieved.

\section{References}

[1] P. McCarthy-Ward, A. Valdar, S. Newstead, and S. Revell, "5G new business opportunities", J. of the Institute of Telecommun. Profess., vol. 13, no. 4, pp. 19-25, 2019 [Online]. Available: http://www.fitce2020.pl/5G-New\%20Business\%20Opportunities $\% 20$ FITCE\% 202020\%20pdf.pdf

[2] A. Sutton and R. Tafazolli, " $5 \mathrm{G}$ The future of mobile communications, J. of the Institute of Telecommun. Profess., vol. 9, no. 1, pp. 10-16, 2015.

[3] A. Sutton, "Deployment of the EE 5G network", J. of the Institute of Telecommun. Profess., vol. 13, no. 4, pp. 27-31. 2019 [Online]. Available: https://www.academia.edu/41625209/ Design_and_Deployment_of_the_EE_5G_Network

[4] "5G forecast report from Ovum. Global 5G Subscription Forecast 2019-2022", Telecom Statistics, Telecomlead, 23 March 2018. [Online]. Available: http://www.telecomlead.com/telecomstatistics/ 5g-forecast-report-from-ovum-83098

[5] "Cisco Visual Networking Index: Global Mobile Data Traffic Forecast Update, 2016-2021, White Paper", Czech Marketplace, 2017. [Online]. Available: http://www.czechmarketplace.cz/news/ cisco-visual-networking-index-global-mobile-data-traffic-forecastupdate-2016-2021-white-paper

[6] A. Andonian, A. Karlsson, A. Axel, and K. Nonaka, "Japan at a Crossroads: The 4G to 5G (R)evolution”, McKinsey, Jan. 2018. [Online] Available at: https://www.mckinsey.com/industries/ technology-media-and-telecommunications/our-insights/ japan-at-a-crossroads-the-4g-to-5g-revolution

[7] M. Collins, A. Das, A. Menard, and D. Patel, "Are you ready for 5G?", McKinsey, 2018 [Online]. Available:

https://www.mckinsey.com/industries/telecommunications/ our-insights/are-you-ready-for-5g

[8] S. Temple, "5G and demand alternative network principles", J. of the Institute of Telecommun. Profess., vol. 9, no. 1, pp. 18-21, 2015.

[9] A. Sutton, "5G rollout, performance and next steps", ITP Seminar The Reality of 5G, Nov. 2019.

[10] F. Gripink, A. Ménard, H. Siguardsson, and N. Vucevic, "Network sharing and 5G: A turning point for lone riders", McKinsey, Feb. 2018 [Online]. Available: https://www.mckinsey.com/industries/ telecommunications/our-insights/network-sharing-and-5g-a-turningpoint-for-lone-riders

[11] E. A. Smith and M. Ugolini, "Rolling out smart meters in Europe", J. of the Institute of Telecommun. Profess., vol. 11, no. 1, pp. 19-24, 2017.

[12] M. Ugolini and E. Smith, "Il mercato della banda ultralarga in Europa", Rivista AEIT, vol. 104, no. 3/4, pp. 12-21, 2019 [Online]. Available: https://www.aeit.it/aeit/edicola/aeit/aeit2019/ aeit2019_02_cisa/aeit2019_02_riv.pdf [in Italian]

[13] M. Ugolini and E. Smith, "The market potential of 5G: An AngloItalian view", Rivista AEIT, vol. 104, no. 1/2, pp. 48-55, 2019 [Online]. Available: https://www.aeit.it/aeit/edicola/aeit/aeit2019/ aeit2019_01_cisa/aeit2019_01_riv.pdf [in Italian]

[14] Cisco Annual Internet Report (2018-2023) [Online]. Available: https://www.cisco.com/c/en/us/solutions/collateral/ executive-perspectives/annual-internet-report/ white-paper-c11-741490.html

[15] D. Littmann, P. Wilson, C. Wigginton, B. Haan, and J. Fritz, "5G: The chance to lead for a decade", Report, Deloitte Consulting LLP, 2018 [Online]. Available: https://www2.deloitte.com/content/dam/ Deloitte/us/Documents/technology-media-telecommunications/ us-tmt-5g-deployment-imperative.pdf

[16] CMR Communications Market Report, Ofcom, 2 Aug. 2018 [Online]. Available: https://www.ofcom.org.uk/__data/assets/ pdf_file/0022/117256/CMR-2018-narrative-report.pdf
[17] Mobile matters, Researching people's experience of using Android mobile services, Ofcom, 10 October 2019 [Online]. Available: https://www.ofcom.org.uk/__data/assets/pdf_file/0038/169769/ mobile-matters-report.pdf

[18] A. Weissberger, "Gartner: 5G IoT endpoints to triple between 2020 and 2021; Surveillance cameras to be largest market over next 3 years", IEEE ComSoc Technology Blog, 17 Oct. 2019 [Online]. Available: https://techblog.comsoc.org/2019/10/17/ gartner-5g-iot-endpoints-to-triple-between-2020-and-2021surveillance-cameras-to-be-largest-market-over-next-3-years/

[19] Collection of congress papers "2019 CTTE-FITCE: Smart Cities \& Information and Communication Technology (CTTE-FITCE)" [Online]. Available: https://ieeexplore.ieee.org/xpl/conhome/ 8890754/proceeding

[20] M. Ugolini and E. A. Smith, "Closer look to the future of smart cities", in Proc. of 2019 CTTE-FITCE: Smart Cities \& Inform. and Commun. Technol., Ghent, Belgium, 2019 (DOI: 10.1109/CTTE-FITCE.2019.8894827).

[21] "The Tactile Internet", ITU-T Technology Watch Report, August 2014 [Online]. Available: https://www.itu.int/dms_pub/ itu-t/oth/23/01/T23010000230001PDFE.pdf

[22] ITP Seminar - The Reality of 5G, ITP Seminar Round Table Debate, London, November 2019.

[23] S. Newstead, "5G or not 5G? That is the question", J. of the Institute of Telecommun. Profess., vol. 13, no. 4, pp. 9-16, 2019.

[24] T. Degrande, F. Vannieuwenborg, S. Verbrugge, and D. Colle, "Adoption of cooperative intelligent transport systems in Flemish passenger cars: A review of European policy options", in CTTEFITCE: Smart Cities \& Information and Communication Technology, Ghent, Belgium, 2019 (DOI: 10.1109/CTTE-FITCE.2019.8894817).

[25] P. G. W. Keen and R. Mackintosh, The Freedom Economy. Berkeley: McGraw-Hill, 2001, pp. 30-33 (ISBN: 9780072133677).

[26] S. O’Dea, Global smartphones sales to end-users 2007-2020, 28 Feb. 2020 [Online]. Available: https://www.statista.com/ statistics/263437/global-smartphone-sales-to-end-users-since-2007

[27] Facebook Revenue 2009-2020 | FB, Macrotrends [Online]. Available: https://www.macrotrends.net/stocks/charts/FB/ facebook/revenue

[28] Netflix Revenue 2006-2020 | NFLX, Macrotrends [Online]. Available: https://www.macrotrends.net/stocks/charts/NFLX/ netflix/revenue

[29] F. Grijpink, T. Härlin, H. Lung, and A. Ménard, "Cutting through the 5G hype: Survey shows telcos' nuanced views", McKinsey Insights, Feb. 2019 [Online]. Available: https://www.mckinsey.com/ industries/technology-media-and-telecommunications/ our-insights/cutting-through-the-5g-hype-survey-shows-telcosnuanced-views

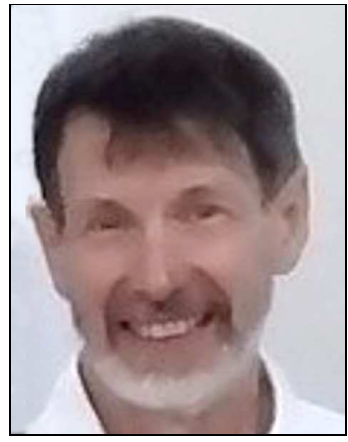

Edward Smith retired from BT in May 2016, and now focuses on research in network modeling, telecommunications history and the development of new ICT propositions. He partners with researchers in the UK and Italy on a range of projects. In his professional life he has worked with major clients across a wide range of technologies, having first developed IT skills with United Biscuits handling real time process control systems and Elida Gibbs, developing transaction processing middleware and data communications solutions. He holds B.Sc. and $\mathrm{Ph} . \mathrm{D}$. degrees from the University of Leicester and a Post Graduate Certificate in Commercial Management from De 
Montfort University. He is a Fellow of the British Computer Society, a Chartered Information Technology Practitioner, a Chartered Engineer, ISEB accredited consultant and a TOGAF accredited Enterprise Architect.

(iD) https://orcid.org/0000-0003-0896-0455

E-mail: edward.a.smith@btinternet.com

Wokingham U3A

Wokingham, United Kingdom

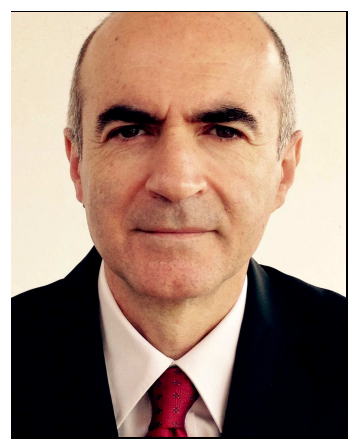

Mauro Ugolini is an expert in business innovation and in process digitalization, who has held several executive positions in global ICT companies. A pioneer of the Mobile Internet development, he has launched several hi-tech startups. He graduated in Physics (cum laude) at Sapienza University of Rome, gained an
Executive MBA from Alma Graduate School at University of Bologna and earned a Ph.D. in Telecommunication Engineering at Roma Tre University. He is a consultant for business development and innovation lecturer for Italy's Ministry of Education, University and Research (MIUR). $\mathrm{He}$ is also a chartered Master in Economics, General Management and Market Management and a recognized author of works in the fields of Information Technology, Management and Communication. As a courtesy professor of the Engineering Department at Roma Tre University, he is focused on the research for the development of the Networked Society, pursued with the aim of increasing the responsibility and sustainability levels in the current global economy, through the analysis and the study of the properties of the so called networked digital ecosystems.

E-mail: mauro.ugolini@uniroma3.it

Department of Engineering

Roma Tre University

Rome, Italy 